\title{
АНАЛИЗ СОВРЕМЕННОГО СОСТОЯНИЯ ИССЛЕДОВАНИЙ И ПРАКТИКИ ПРИМЕНЕНИЯ МЕТОДА ВЗАИМНОГО ОЦЕНИВАНИЯ В ОБУЧЕНИИ СТУДЕНТОВ ВЫСШЕЙ ШКОЛЫ
}

\author{
Ю.С. Третьякова \\ Московский гуманитарный университет
}

\begin{abstract}
Аннотация: На основании анализа российских и зарубежных источников определяются условия эффективного применения метода взаимной оценки, формулируются преимуществв $u$ ограничения данного метода, а также перспектива его использования в условиях электронного обучения.
\end{abstract}

Ключевые слова: взаимное оченивание, взаимное рецензирование, электронное обучение

\section{THE ANALYSIS OF CURRENT RESEARCHES AND PRACTICE OF PEER ASSESSMENT IN HIGHER EDUCATION}

\author{
J.S. Tretyakova \\ Moscow University for the Humanities
}

\begin{abstract}
In the article the conditions for the effective application of peer assessment are determined based on the analysis of Russian and foreign sources, the advantages and limitations of this method are formulated, as well as the prospect of its using in e-learning
\end{abstract}

Keywords: peer assessment, peer review, e-learning

С внедрением новых образовательных стандартов высшее образование в России претерпевает значительные изменения. Его массовая доступность, обширное использование дистанционных и компьютерных технологий в обучении, усиление роли самостоятельной познавательной деятельности студента влияют на количество и качество взаимодействия всех субъектов учебного процесса. Происходит постепенное изменение роли преподавателя с ведущей на тьюторскую, повышается значимость профессиональной социализации.

При ориентации образования на активное участие студентов в обучении и внедрении компетентностного подхода резко увеличилось количество выполняемых студентами работ, направленных на практическое применение полученных знаний, и одновременно с этим сузились возможности для подробной конструктивной обратной связи от преподавателя к обучающемуся.

В условиях смены образовательной парадигмы время учителя становится критическим ресурсом. П. Садлер, Е. Гуд и др. отмечают, что открытые вопросы в работах студентов требуют много времени и усилий для рассмотрения, высказывания замечаний и последующей оценки, вследствие чего преподаватели зачастую выбирают неоптимальные задания, не предоставляющие возможности проверить всю глубину знаний и степень понимания изучаемого предмета, при условии, что эти задания легче оценивать (Sadler, Good, 2006: 2). 
Одним из возможных решений данной проблемы может стать вовлечение студентов в те виды обучения, которые предполагают активное взаимодействие друг с другом, а также делегирование полномочий оценивания самим обучающимся, что позволит повысить учебную мотивацию. Эту задачу может решить внедрение взаимного оценивания (Peer assessment, Peer review) студентами различных письменных и устных работ.

Целью настоящей статьи является анализ исследований и практики применения метода взаимного оценивания в обучении студентов высшей школы.

Взаимное оценивание не является инновацией в современной педагогике, но оно стало широко использоваться последние 30 лет в дистанционном обучении, в массовых открытых онлайн-курсах (МООС), в университетах Великобритании, США, Австралии, Канады. Взаимное оценивание являлось частью системы А. Белла и Дж. Ланкастера в английской школе начала XIX в., в системе развивающего обучения Дьяченко описывается классическая технология взаимного оценивания, она же привела Дж. Сименса и С. Даунса к созданию теории коннективизма (сетевого обучения).

Ряд исследователей отмечают растущий интерес к педагогике со вкладом учащихся (CSP, Contributing Student Pedagogy), т.е. к педагогике, побуждающей студентов вносить свой вклад в обучение других и ценить вклад других студентов (Hamer, Cutts, Jackova и др., 2008: 95).

При этом интересы преподавателей, использующих метод взаимной оценки, и авторов научных трудов, исследующих проблемы взаимного оценивания, можно отнести фактически к одному из двух глобальных вопросов:

1. Взаимное оценивание как замена оценки преподавателя, что включает в себя решение проблемы достоверности и валидности оценки, повышает качество работы студента как оценивающего эксперта (отбрасывание грубых ошибок и оценка работы эксперта), конструирование условий, способных повысить точность и качество взаимной оценки, математические и статистические методы анализа результатов оценивания, разработку методик, а также программного обеспечения для качественной взаимной оценки.

2. Взаимное оценивание как инструмент самообучения, что предполагает измерение обучающего эффекта для студента, находящегося в роли оценивающего эксперта, формирование у него ключевых профессиональных компетенций - оценки работы подчиненных, навыков экспертизы и принятия решений, возможности осуществлять конструктивную обратную связь, а также повышать учебную мотивацию, формировать благоприятную учебную обстановку, создавать учебные сообщества.

П. Садлер и Е. Гуд как один из аспектов взаимного оценивания рассматривают самооценку (self-grading) студентом своей работы, осуществляемую по той же методике и в тех же условиях, что и взаимное оценивание (peer-grading). При этом в своем исследовании они приходят к выводу, что самооценка всегда способствует более глубокому пониманию изучаемой темы, в то время как взаимная оценка приводит к 
значительным улучшениям результатов обучения у групп студентов нижнего и среднего (но не высокого) уровня обученности (Sadler, Good, 2006: 3).

Основными методами, используемыми при изучении проблем взаимного оценивания, являются кейс-стади (от англ. case study - разновидность монографического научного исследования, объектом которого выступает один или несколько случаев) и включенное неформализованное наблюдение (Арлашкина, 2018: 133), систематизированный обзор научной литературы (Luxton-Reilly, 2009: 2), математический и статистический анализ результатов констатирующих и формирующих экспериментов, а также построение математических моделей (Карпенко и др., 2014: 7).

Ряд исследователей (О.В. Арлашкина, П. Садлер и др.) под взаимным оцениванием подразумевают процесс, когда студенты ставят оценку друг другу за тесты или задания по схеме, заданной преподавателем, причем зачастую имеется в виду оценка в баллах, иногда дополняемая комментариями к проверяемой работе и/или рецензией на нее. Нам представляется разумным определить взаимное оценивание обобщенно, так, как сделала это К. Топпинг (Topping, 1998: 250): взаимное оценивание - это договоренность, согласно которой обучающиеся рассматривают количество, уровень, значимость, ценность, качество, успешность результатов обучения других обучающихся с аналогичным статусом. К. Топпинг подчеркивала, что взаимное оценивание используется в разных контекстах и может приводить к повышению когнитивных, социальных, эмоциональных, профессиональных навыков и системных знаний в отдельных областях (Topping, 1998: 251).

Эффективное применение метода взаимного оценивания предполагает соблюдение определенных условий. Основные условия, отмечаемые большинством исследователей проблемы - принцип анонимности (для проверки предоставляются анонимные, оформленные в едином стиле работы) и четкие детализированные критерии оценки, которые разъясняются студентам до начала оценивания (эти же критерии должны использоваться самим преподавателем при оценке студенческих работ). Анонимность уменьшает обеспокоенность студентов предвзятостью и необъективностью оценки (Ballantyne, 2002: 431), что приводит к благоприятной психологической обстановке, а также повышает объективность обратной связи. Как вариант принципа анонимности возможны работы, в которых имя автора известно группе проверяющих, но при этом гарантируется анонимность самих проверяющих.

К разработке критериев оценки работ студентов существует множество подходов. Ответственность за решение этой задачи лежит на преподавателе, но многие авторы подчеркивают, что целесообразно критерии обсуждать со студентами до начала процесса взаимной оценки. Разработка критериев оценки вместе со студентами требует обсуждения каждого вопроса теста и существенных характеристик правильных ответов. В ситуации, если проверочная работа носит не тестовый характер, то совместная выработка критериев еще более трудоемка и требует больших временных затрат. При этом следует согласиться с точкой зрения В.3. Юсупова о 
Научные труды Московского гуманитарного университета

2020 № 4

необходимости «поиска оптимального соотношения технологизированных и творческих элементов образовательного процесса» (Юсупов, 2019: 120).

Преподаватель должен организовать работу студентов при взаимном оценивании: обосновать необходимость взаимного оценивания, объяснить возлагаемые на них ожидания и преимущества участия в данном виде контроля, ознакомить студентов с процедурой оценивания (взаимная оценка будет сильнее коррелировать с оценкой преподавателем, если студенты ранее работали по данной процедуре), обсудить точность и приемлемость ответов на типовые задания в учебных группах, разъяснить принципы выставления итоговой оценки, а также предложить поощрение за корректное оценивание. Предварительная тренировка в использовании критериев необходима для корректной взаимной оценки, без нее студенты склонны к игнорированию этих критериев.

Как отмечает П. Садлер, при наделении студентов возможностью использовать открытые качественные высказывания при оценке, вместо того, чтобы руководствоваться четкими официальными рекомендациями, их высказывания становятся слишком краткими или неясными до полной потери смысла оценивания (Sadler, Good, 2006: 8). Тренировка же приводит к изначальному снижению когнитивной сложности и эмоционального накала при взаимном оценивании. Далее предполагается невмешательство преподавателя в процесс оценивания, за исключением модерирования дискуссий и соблюдения регламентов, чтобы не вызвать демотивации участников взаимного оценивания.

Н. Фалчиков и Дж. Голдфинч провели мета-анализ, исследуя валидность оценок при взаимном оценивании, сравнивая оценки студентов с оценками преподавателя. Они рекомендовали использование одной оценки за работу вместо множества оценок по разным измерениям (ключевым критериям) (Falchikov, Goldfinch, 2000). Другие исследователи (Miller, 2003) отмечают, что критерии, предполагающие возможность комментировать, выявляют большее число качественных отзывов, как и большее число комментариев в целом. При этом отмечается, что четкое деление между объективными и субъективными критериями улучшает качество отзыва на работу при взаимной оценке.

Студентам нравится иметь возможность высказывать свою личную точку зрения (не вносящую вклад в итоговую оценку). Отделение этой частной точки зрения от объективных критериев оценивания повышают корреляцию студенческой оценки с преподавательской. Для ряда работ (написание эссе и т.п.) нужно предусмотреть возможность написания нескольких драфтов (версий работы, разной степени детализации - план, набросок, проект, черновик) и правки работы по результатам комментариев студентов после каждого из этапов, с выставлением оценки за итоговую версию работы.

Качество взаимной оценки - один из аспектов процедуры, вызывающих озабоченность, как у студентов, так и у преподавателей. Для разрешения данной проблемы у преподавателя должна быть возможность оценить качество взаимной оценки, 
а у автора работы должна быть возможность обсудить спорные с его точки зрения моменты в учебной группе. Для ряда работ также возможна организация дискуссионных групп.

Изучая опыт применения взаимного оценивания, можно прийти к выводу, что данный метод имеет как явные преимущества, оказывая позитивное воздействие на среду и процесс обучения студентов, так и некоторые негативные эффекты, обусловленные в основном психологическими особенностями участников образовательного процесса и сложностью разработки критериальной системы оценивания.

К преимуществам метода можно отнести следующее:

- преподаватель тратит меньше времени на проверку работ, студент получает быструю обратную связь. При взаимном оценивании студенты зачастую тратят большее количество времени на оценку работы, чем потратил бы преподаватель, и дают более детальные комментарии;

- студенты лучше понимают критерии оценивания, а также видят сильные стороны и недочеты собственной работы через оценивание работ других;

- у студента меняется отношение к оценке, оценивание начинает трактоваться как часть процесса обучения, ошибки перестают рассматриваться как неудача, они становятся еще одной возможностью получить полезную обратную связь;

- при оценивании презентаций и выступлений у студентов повышается внимание и интерес к групповым мероприятиям;

- снижается количество оценок, выставляемых педагогами, но при этом у студентов появляется чувство сопричастности и ответственности за учебу всей группы, растет учебная мотивация, формируется активная позиция по отношению к учебе;

- формируются учебные сообщества с атмосферой сотрудничества, появляется возможность изменить свое видение вопроса под воздействием комментариев других, получить толчок к развитию;

- развиваются навыки анализа и оценивания, используется оценка других для создания модели самооценки;

- появляется более глубокое понимание темы.

К минусам применения взаимного оценивания можно отнести следующее:

- существует тенденция недооценивать других при взаимном оценивании, тогда как при самооценке студенты склонны переоценивать себя (Sadler, Good и др., 2006: 15);

- значительное улучшение результатов обучения наблюдается только у групп студентов нижнего и среднего уровня обученности, у группы высокого уровня обученности результаты незначительно отличались от контрольной группы (Там же: 19);

- при отсутствии разъяснений со стороны преподавателя студенты не всегда понимают критерии оценивания, студентам низкого уровня обученности могут быть неясны критерии оценивания в принципе. При непонимании критериев студенты игнорируют их в процессе взаимного оценивания;

- «некоторые студенты болезненно воспринимают отстраненность преподава- 
теля, подозревая соучеников в некомпетентности или намеренной агрессии» (Арлашкина, 2018: 136);

- необходимость оценивания качества работы студента, как проверяющего эксперта;

- определенная доля студентов ставит оценки без анализа работы, случайным образом, но грубые ошибки можно нивелировать при обработке результатов;

- сложность оценивания устных работ.

Как отмечает А. Лакстон-Рейли, метод взаимной оценки показывает высокий уровень валидности и надежности, студенты считают его достаточно честным и точным (Luxton-Reilly, 2009: 1). По мнению O.В. Арлашкиной, «большая часть студентов относится к оцениванию других ответственно, выставляя продуманные оценки, не более чем на 5\% отличаются от преподавательской» (Арлашкина, 2018: 137). К примеру, исследователи приводят следующий результат: корреляция оценок при взаимной оценке с оценкой учителем 0,905, при самооценке 0,976 (Sadler, Good и др. 2006: 24).

Взаимное оценивание может внести большой вклад в результативность процесса обучения в высшей школе. Электронные образовательные ресурсы (ЭОР) могут снизить сложность внедрения и администрирования данного вида групповой работы студентов, обеспечивая необходимую поддержку. ЭОР позволяют использовать взаимное оценивания для больших учебных групп, включая и открытые онлайн-курсы. Более того, реализация в ЭОР таких технологий, как анонимные онлайн-дискуссии, расчет средневзвешенной оценки, автоматизация документооборота и т.п. не может быть обеспечена в традиционных письменных или очных сессиях взаимного оценивания.

А. Лакстон-Рейли подчеркивает, что по мнению студентов, при личном общении проще коммуницировать, но давать подсказки и помогающую обратную связь удобнее при использовании онлайн-ресурсов (Luxton-Reilly, 2009: 2). Взаимное оценивание активно применяется при дистанционном и электронном обучении, оно позволяет оценивать виды работ, которые не поддаются автоматизированной проверке (творческие работы и эссе, программный код, схемы, презентации и т.п.).

Современный деятельностный подход в обучении, явные тенденции к увеличению времени на самостоятельную работу в процессе обучения требуют от преподавателя создания среды, способствующей формированию и развитию у студентов универсальных и профессиональных компетенций, навыков критического анализа и конструктивного взаимодействия внутри профессионального сообщества. Эффективным элементом этой среды может являться применение метода взаимного оценивания. Взаимное оценивание фиксирует внимание на объективной стороне контроля результатов обучения, способствует развитию навыка самооценки, уточнению и приведению в систему собственных знаний, а также повышает учебную мотивацию.

Данный метод становится все более востребованным с повсеместным внедре- 
нием электронного обучения. Имея определенные ограничения, он, тем не менее, обладает рядом важных достоинств, таких как освоение студентами навыков экспертизы и написания отзывов на работы других обучающихся, более глубокое понимание изучаемой темы, а также оптимизация времени преподавателя.

\section{СПИСОК ЛИТЕРАТУРЫ}

Арлашкина, О.В. (2018) Применение метода взаимного оценивания в обучении менеджменту //Вестник Нижегородского университета им. Н.И. Лобачевского. Серия: Социальные науки. № 2. С. 132-141.

Карпенко, М.П., Басов, В.А., Семенова, Т.Ю. и др. (2014) Проблемы взаимного оценивания в учебной работе студентов //Социология образования. № 6. С. 4-13.

Юсупов, В.3. (2019) Междисциплинарный подход к разработке технологий оценивания сформированности компетенций в условиях реализации ФГОС $3++/ /$ Высшее образование для XXI века: роль гуманитарного образования в контексте технологических и социокультурных изменений: XV Международная научная конференция, МосГУ, 14-16 ноября 2019 г.: Доклады и материалы : в 2 ч. Ч. 2. / под общ. ред. И.М. Ильинского. М.: МосГУ. С. 118-124.

Ballantyne, R., Hughes, K., Mylonas, A. (2002). Developing Procedures for Implementing Peer Assessment in Large Classes Using an Action Research Process. Assessment \& Evaluation in Higher Education, 27(5), p. 427-441.

Falchikov, N., \& Goldfinch, J. (2000). Student Peer Assessment in Higher Education: A Meta Analysis Comparing Peer and Teacher Marks. Review of Educational Research, 70(3), p. 287-322.

Hamer, J., Cutts, Q., Jackova, J., Luxton-Reilly, A., McCartney, R., Purchase, H., et al. (2008). Contributing student pedagogy. SIGCSE Bull., 40(4), p. 194-212.

Luxton-Reilly, A. (2009) Systematic Review of Tools that Support Peer Assessment //Computer Science Education. December.

Miller, P.J. (2003). The Effect of Scoring Criteria Specificity on Peer and Self-assessment. Assessment \& Evaluation in Higher Education, 28(4), 383-394.

Sadler, P., Good, E. (2006) The Impact of Self- and Peer-Grading on Student Learning // Educational Assessment. 11.1. p. 1-31. [Электронный ресурc] URL: https://www. cfa.harvard.edu/sed/staff/Sadler/articles/Sadler\%20and\% 20Good\%20EA.pdf (Дата обращения: 06.07.2020).

Topping, K. (1998). Peer Assessment Between Students in Colleges and Universities. Reviewof Educational Research, 68(3), p. 249-276.

Третьякова Юлия Сергеевна - обучающаяся 3 курса образовательной программы магистратуры по направлению подготовки 44.04.02 Психолого-педагогическое образование Московского гуманитарного университета. Научный руководитель - д.п.н., проф. Юсупов В.З. Адрес: 111395, Россия, г. Москва, ул. Юности, д. 5. Тел.: +7 (499) 374-74-59. Эл. адрес: kafedra@mosgu.ru. 
Tretyakova Yulia Sergeevna is a 3rd-year student of the master's degree program in the field of training 44.04.02 Psych - pedagogical education of the Moscow University for the Humanities. Scientific supervisor-doctor of science, prof. Yusupov V.Z. Postal address: 5 Yunosti str., Moscow, 111395, Russian Federation. Tel: +7 (499) 374-74-59. E-mail: kafedra@mosgu.ru.

Третьякова Ю.С. Анализ современного состояния исследований и практики применения метода взаимного оценивания в обучении студентов высшей школы // Научные труды Московского гуманитарного университета. 2020. №4. C. 69-76. DOI: https://www.doi.org/ 10.17805/trudy.2020.4.10 